\title{
Modification level and test of scientific argumentation skill: Development and validity
}

\author{
Riki Perdana ${ }^{1}$, Riwayani ${ }^{2}$, Jumadi Jumadi ${ }^{3}$, Dadan Rosana ${ }^{4}$ \\ ${ }^{1}$ Faculty of Teacher Training and Education, Universitas Alma Ata, Indonesia \\ 2,3,4 Physics Education Departement, Universitas Negeri Yogyakarta, Indonesia
}

\section{Article Info \\ Article history: \\ Received Mar 17, 2020 \\ Revised Jul 13, 2020 \\ Accepted Aug 5, 2020}

\section{Keywords:}

Development test

Scientific argumentation

Validity test

\begin{abstract}
This study focuses on developing the new level of scientific argumentation skills and new items that are feasible and valid for used. There are 195 science students at Islamic State School 1 (MAN 1) Yogyakarta as participant in this study. Random sampling technique was used from the three schools of Islamis State School (MAN) in Yogyakarta, Indonesia. There are seven experts ( 3 Professor, 2 teachers, and 2 graduate students) reviewed 14 items for the first phase of this study. For the second phase, 98 students answered 14 questions which each questions contain five point (claim, data, backing, warrant and rebuttal). For the third phase, after choosed the best five 5 questions, We asked the others (97 students) to answer those questions. The modification of the level of scientific argumentation skills indicates the ability of students is still low. At level 1 (claims) there were only $38.9 \%$ students, level 2 (data) were $21.6 \%$ students, level 3 (warrants) $16.6 \%$ students, level 4 (backing) $16.2 \%$ while level 5 (rebuttal) is the most difficult, for students' users only by $4.2 \%$. Based on the findings, the test can measure and show with a separate level of students' scientific argumentation skill in this school.
\end{abstract}

This is an open access article under the CC BY-SA license.

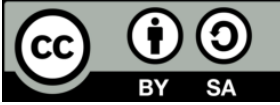

\section{Corresponding Author:}

Riki Perdana,

Faculty of Teacher Training and Education,

Universitas Alma Ata,

Jl. Brawijaya No.99, Jadan, Tamantirto, Bantul, Yogyakarta, Indonesia.

Email: rikiperdana@almaata.ac.id

\section{INTRODUCTION}

Scientific argumentation skill has been developed in the field of science education. This is a form of acquiring knowledge about the role of communication in science and scientific knowledge [1]. According to Scarmadalia [2], said that the development of expertise supported by students in dialogue and continuous discourse to increase support in the community. In this discussion, students must engage in discussions to support their claims and in conversation to debate like scientists.

Argumentation skill is essential for students because it can build explanations as a basis. Conceptual knowledge of students is better developed in the context of argument-based learning [3]. The results of the study [4] showed that students who received the teaching of argumentation outperformed their peers who received traditional participation with punishment skills. Scientific arguments are fundamental in learning. According to [5] science conversation consists of four interrelated aspects: 1) students can discuss scientific explanations to solve problems about world of science; 2) students can produce and discuss scientific reason and arguments; 3) Students can know and describe the nature of science and how to develop knowledge; 4) students who are able to understand the concepts and can argue in scientific practice. 
Scientific arguments are exciting in education. According to Mirza and Perret-Clermont [6] the case for explorative, critical and questioning is about scientific exploration challenges. He added, the evidence of the invited students to use and dispute the rules of punishment used in scientific work: students look for reasons, discuss the data, examine alternative hypotheses, and others discuss specific thoughts. In science, the relationship between evidence and claims were extracted by the argumentation as a form of logical discourse [7].

Hsu, Chiu, Lin, and Wang [7] said arguments relevant in the context of education because this helps learners extract the relationship between changing, changing Reviews their conceptions, and allowing claims. According to [7], not only science educator believe the skill as a scientific practice that must learn by students, but argumentation also building the explanation from the students. There are two playing keys to involving students in scientific argumentation [8]. First, argumentation is the primary practice of science, and as such must become the focus and centre of science education. Second, discuss the norms of this skill, can lead students to understand the theory of epistemology foundations of scientific practice.

The ability to communicate cannot be separated from the quality of the arguments presented. Thus, the strength of scientific argumentation becomes very important in learning physics. However, Wardani et. al [9] found that students' scientific arguments are still able to Make claims but have not been able to determine warrants. Students also cannot provide concepts that support claims correctly [10]. However, in Indonesia, there are not many researches on students' scientific argumentation skills. Some existing research also has not shown the level of this skill. While it is imperative to understand student levels so that it is known that efforts can be made to improve this ability. Therefore, this research aims to develop a new level and test of scientific argumentation skill. The research question in this study are (1) what the criteria for the level of scientific argumentation abilities of students are? (2) How about the feasibility of the questions developed to measure students' scientific argumentation skills? (3) What is the level of technical argumentation abilities of students in Indonesia?

The components in the argumentation skill according to [11] consist of five aspects accordingly, 1) Claim: claimed according to the wish submitted; 2) basis: reason is the approval needed to support and be given upon request; 3) warrants: This shows the logical relationship between the claim and cause and declaration of problems that are often implied in the argument. 4) Qualifications: Qualifiers are used to communicate beyond where the claims are received; 5) rebuttal: These statements govern the potential to be approved with a statement where the claim may not apply.

The components of scientific argumentation roommates Consist of five aspects: 1) a claim, a statement or opinion about problem-solving; 2) the data, evidence or facts, data, evidence or facts that support the truth of the claim; 3) warrants, claims to receive claims by linking the data, evidence or facts made; 4) support, justification for warrants; and 5) rebuttal, rebuttal to warrants.

The scientific argumentation component according to [12] consists of five elements, 1) facts, facts related to a particular context; 2) warrants, This is part of the argument that connects facts with claims that meet the requirements, 3) Backing, it is a kind of justification for warrants. It explains and give guarantee question as a reason to accept claims that meet the requirements; 4) rebuttal, rebuttal explains the circumstances that will be considered as an exception to warrants; 5) claims that fulfil the conditions, claims that qualify, conclusions that can be drawn, and the warranty is valid, and the rebuttal does not apply.

\section{RESEARCH METHOD}

The first stage in developing a scientific argumentation skills test is to define this skill and choose what aspects will be needed. Based on the results of the literature review analysis, the proposed points are based on the elements of scientific argumentation skills delivered by Osborne, Erduran, and Simon [13] as shown in Table 1.

Table 1. Level of scientific argumentation skill

\begin{tabular}{|c|c|}
\hline Level & Description \\
\hline 1 & Argumentation consists of arguments that are a simple claim vs counterclaim or a claim vs claim \\
\hline 2 & $\begin{array}{l}\text { Argumentation has cases comprising claims with either the data, warrants or backings but does not contain any } \\
\text { rebuttals }\end{array}$ \\
\hline 3 & $\begin{array}{l}\text { Argumentation has discussion with a series of claims or counterclaims with either the data, warrants or backings } \\
\text { with the occasional weak rebuttal. }\end{array}$ \\
\hline 4 & $\begin{array}{l}\text { Argumentation shows arguments with a claim identifiable with a rebuttal. Such an argument may have Several } \\
\text { claims and counterclaims as well, but this is not Necessary }\end{array}$ \\
\hline 5 & Argumentation displays an extended argument with more than one rebuttal \\
\hline
\end{tabular}

Int. J. Eval. \& Res. Educ. Vol. 9, No. 3, September 2020: 769 - 777 


\subsection{Model of research}

There are 195 students of class XI science at Islamic State School 1 (MAN 1) Yogyakarta as participant in this study (Table 2 shows the characteristic of Students). Random sampling technique was used from the three schools of Islamis State School (MAN) in Yogyakarta (MAN 1, MAN 2 and MAN 3). We choosed class XI because the topic of Gravitational Newtons'Law is in this class on Indonesia Curriculum. For the first phase, there are seven experts (3 Professor, 2 teachers, and 2 graduate students) reviewed 14 items. For the second phase, after revised the items, we asked the 98 students to answered 14 questions which each questions contain five point (claim, data, backing, warrant and rebuttal). We analysed their answer to get data of reliability, validity, and difficulty items. For the third phase, after choosed the best five 5 questions, We asked the others (97 students) to answer those questions. We used this result to investigate the level of student'scientific argumentation skill.

Table 2. Charateristic of students

\begin{tabular}{cl}
\hline Aspect & \multicolumn{1}{c}{ Descriptions } \\
\hline Ages & $\begin{array}{l}\text { 16-17 years } \\
\text { Formal operational stage } \\
\text { When the teacher provides learning, and contextually connects the problem some students can answer the } \\
\text { Devel of Cognitive } \\
\text { Duestion well. Students are able to think about an object or thing even though it is not in front of them. } \\
\text { During the learning and discussion process, students are also able to examine the problem and draw } \\
\text { conclusions. So that at this stage students can learn coherently and systematically until they are able to } \\
\text { generalize a concept. } \\
\text { Academic skills } \\
\text { exchange ideas and are willing to present their arguments in front of the class (the ability to work together } \\
\text { and communicate) well. However, based on interviews with teachers, the academic skills of many } \\
\text { students are below average. }\end{array}$ \\
\hline
\end{tabular}

\subsection{Item reliability}

Item reliability and validity data were obtained from the results of the students when administrated the second phase. Analysis of Reliability test in this study using the Quest software. The reliability test is determined by looking at the estimated value of the item reliability (item reliability) and case estimation reliability (test reliability). The reliability category according to Sumintono and Widhiarso [14] is shown in Table 3.

\begin{tabular}{cc}
\multicolumn{2}{c}{ Table 3 . Reliability scale } \\
\hline Score & Category \\
\hline$>0.94$ & Excellent \\
0.91 to 0.94 & Very Good \\
0.79 to 0.90 & Good \\
0.67 to 0.80 & Enough \\
$<0.67$ & Weak
\end{tabular}

\subsection{Item validity}

\subsubsection{Content validity}

Content validation is a psychometric procedure that tests the ability of a test to measure variables precisely [15]. This requires a subject of "expert" classification items into one of three criteria: "important," "useful, not important," or "unnecessary". Items that were considered "important" by the total reviewer members were then allowed in the final test with items that failed to reach this level was excluded [16].

This test used to determine the value of the instruments of scientific argumentation skill that has been developed. This test was conducted based on the results of the assessment by the validator by calculating the content validity coefficient developed by Lawshe [17]. Expert criteria consisting of five rules were changed to three criteria of essential, useful but not essential and not useful items. The content validity coefficient is calculated by the coefficient of:

$$
C V R=\left(\frac{n_{e}-\frac{N}{2}}{\frac{N}{2}}\right)
$$

CVR = Content validity ratio (Content validity)

ne $\quad=$ Number of validators who choose items can be used

$\mathrm{N} \quad=$ The total number validator 
The instrument validity for the seven-validator category was 0.99 . If the CVR value is more than 0.99 , the item is accepted as valid. Data was obtained from first phase where there are seven experts (3 Professor, 2 teachers, and 2 graduate students) reviewed 14 items.

\subsubsection{Empirical validity}

This test aims to determine the value of the empirical validity of the matter of the ability of scientific. Data was obtained from the results of the second phase. The empirical validity test in this study uses the Quest software. The item items are stated to be compatible and fit with the Rasch model of INFIT MNSQ if the value is at an interval of $0.77-1.30$. The item items are said to be valid if the INFIT value is within the range of $\pm 2.0[14]$.

\subsection{Item difficulty}

The difficulty level of questions is also analysed in this study. To determine the level of difficulty can be seen from the threshold value or difficulty. Criteria about the difficulty level can be seen in Table 4 .

\begin{tabular}{cc} 
Table 4. Range of difficulty \\
\hline Score & Category \\
\hline $\mathrm{b} \geq 2$ & Very Difficult \\
$1<\mathrm{b} \leq 2$ & Difficult \\
$-1<\mathrm{b} \leq 1$ & Moderate \\
$-1<\mathrm{b} \leq-2$ & Easy \\
$\mathrm{b}<-2$ & Very Easy \\
\hline
\end{tabular}

\section{RESULTS AND DISCUSSION}

In this section, we explain the results of the reliability scale, validity scale of the items, the level of difficulty, and the level of ability of scientific argumentation. At the initial stage, we submit 14 about the scientific arguments that have been validated by experts.

\subsection{First phase (content validity by experts)}

For the first phase, there are seven experts (3 Professor, 2 professional physics teachers, and 2 graduate students) reviewed 14 items. They reviewed the item based on the aspect as shown as on Table 5 . After we revised several items many times, the reviewers finally stated that all items are essential. Than, we calculate the CVR value from the (1). The result for all items is 1.00. According to Lawshe [17], for 7 validators, the minimum of CVR value is 0.99 . So, the results of the validation assessment indicate that all items are valid and essential at level [3]. They can be used to measure the ability of scientific argumentation. 
Table 5. Aspect for content validity

\begin{tabular}{|c|c|c|c|c|c|c|c|c|c|c|c|c|c|c|}
\hline Aspect & \multicolumn{14}{|c|}{ Items } \\
\hline \multicolumn{15}{|l|}{$\begin{array}{c}\text { The contents of items are in accordance } \\
\text { with the measurement objectives } \\
\text { The topic is in accordance with the } \\
\text { competencies and learning material } \\
\text { being studied }\end{array}$} \\
\hline \multicolumn{15}{|l|}{$\begin{array}{l}\text { Limitation of expected questions and } \\
\text { answers is appropriate }\end{array}$} \\
\hline \multicolumn{15}{|l|}{$\begin{array}{c}\text { The instrument for evaluating the ability } \\
\text { of scientific argumentation has an } \\
\text { answer key }\end{array}$} \\
\hline \multicolumn{15}{|l|}{$\begin{array}{l}\text { The instrument for evaluating the ability } \\
\text { of scientific arguments is equipped with } \\
\text { a scoring rubric }\end{array}$} \\
\hline \multicolumn{15}{|l|}{$\begin{array}{c}\text { Work instructions for the questions are } \\
\text { clearly formulated }\end{array}$} \\
\hline \multicolumn{15}{|l|}{$\begin{array}{l}\text { The purpose of the problem is } \\
\text { formulated briefly and clearly }\end{array}$} \\
\hline \multicolumn{15}{|l|}{$\begin{array}{l}\text { The items do not depend on the } \\
\text { previous problem }\end{array}$} \\
\hline \multicolumn{15}{|l|}{$\begin{array}{l}\text { Use question words or commands that } \\
\text { demand descriptive answers }\end{array}$} \\
\hline \multicolumn{15}{|l|}{ Be consistent in using the terms } \\
\hline \multicolumn{15}{|l|}{$\begin{array}{l}\text { symbols and units } \\
\text { Tables, maps, images, graphs or the like } \\
\text { are presented clearly and legibly }\end{array}$} \\
\hline \multicolumn{15}{|l|}{ Item use good and correct language } \\
\hline $\begin{array}{l}\text { Criteria of Experts judgment } \\
\text { [3]: Essential, if each item gets more than } \\
\text { [2]: Usefull, but not essential if each item } \\
\text { [1]: Not usefull, if each item gets a checkl }\end{array}$ & & & & & & & & & & & & & & \\
\hline
\end{tabular}

\subsection{Second phase (empirical valditiy from students test' result) \\ 3.2.1. Item reliability}

For the second phase, after revised the items, we asked the 98 students to answered 14 questions which each questions contain five point (claim, data, backing, warrant and rebuttal). Based on these results, the reliability of the test, reliability of the items estimates and case estimate, respectively, are 0.79 and 0.70 . According to [14] these results indicate that the quality of the items about the ability of the scientific arguments have the reliability and consistency of the answers were pretty good students.

\subsubsection{Item validity}

Scientific argumentation ability test instrument is test description consists of 14 questions. Validation test about the ability of a scientific argument is based on three aspects: the contents, construction and language. Results of the assessment by the validator calculated using the equation content validity ratio (CVR). Results of the assessment instrument validation capabilities scientific argument show that all CVR score is 1.00 by expert review.

According to Lawshe [17] for a validator which amounted to 7 people, the minimum value of the CVR is 0.99. The results of the validation assessment showed that all items are valid and essential and can be used to determine the level of students' scientific argumentation skills. The test of validity items was used by empirical scientific argument capabilities using the Quest. The validity of the test results, as shown in Table 6.

Item fit with Rasch models if INFIT MNSQ is in the interval from 0.77 to 1.30 . Item is considered valid if the value INFIT $t$ lies in the range limits of \pm 2.0 [14]. The results of the empirical validity of the test items scientific arguments indicate that question number 5 is not compatible with Rasch models invalid and so cannot be used. 


\begin{tabular}{ccccc}
\multicolumn{5}{c}{ Table 6. Result of validity test } \\
\hline Item & Infit MNSQ & Criteria & Infit t & Criteria \\
\hline 1 & 1.23 & Fit & 1.1 & valid \\
2 & 1.27 & Fit & 1.9 & valid \\
3 & 0.86 & Fit & -1.0 & valid \\
4 & 0.84 & Fit & -1.2 & valid \\
5 & 0.71 & Not Fit & -2.3 & Not valid \\
6 & 0.86 & Fit & -1.0 & valid \\
7 & 0.81 & Fit & -0.9 & valid \\
8 & 1.13 & Fit & 0.7 & valid \\
9 & 1.03 & Fit & 0.3 & valid \\
10 & 1.07 & Fit & 0.3 & valid \\
11 & 1.01 & Fit & 0.3 & valid \\
12 & 1.01 & Fit & 0.3 & valid \\
13 & 1.01 & Fit & 0.2 & valid \\
14 & 1.06 & Fit & 0.3 & valid \\
\hline
\end{tabular}

\subsubsection{Item difficulty}

The difficulty item is a very important indicator for teachers and researchers in the field of test development. The item difficulty shows the comparison of the correct answer to the total items. This study uses the QUEST application to calculate the value of item difficulty. The results of the item difficulty can be seen in Table 7.

Table 7. Result of item difficulty

\begin{tabular}{ccc}
\hline Item & Difficulty & Description \\
\hline 1 & -1.47 & Easy \\
2 & -0.93 & moderate \\
3 & -1.02 & Easy \\
4 & -0.97 & moderate \\
5 & -0.81 & moderate \\
6 & -0.61 & moderate \\
7 & -0.60 & moderate \\
8 & -0.36 & moderate \\
9 & 0.90 & moderate \\
10 & -0.51 & moderate \\
11 & 0.89 & moderate \\
12 & 2.95 & Very difficult \\
13 & $2: 30$ & Very difficult \\
14 & $0: 23$ & moderate \\
\hline
\end{tabular}

\subsection{Third phase (implementation test)}

For the third phase, after choosed the best five 5 questions consisting five point to ansered (claim, data, backing, warrant, rebuttal), the instrument was tested on 97 students to measure students' skills of scientific argumentation. They are students majoring in science with an age range of $16-17$ years. The results of the students' answers are then analysed to obtain the results of the scientific argumentation skill level of students. The item consisted of $40 \%$ about the easy type (item 1st and 4th), $40 \%$ about the medium type (item 8 th and 11 th) and $20 \%$ about a very difficult type (item 13). The selection of items is also adjusted to the indicator problem.

Based on the five questions given, the average scores obtained by students are only for 19.83/100. This demonstrates the ability to answer the scientific test argument is still very low. The highest scores are in item 1 with a score of $44.3 / 100$, while the lowest is in the item about 4 with a score of 7.42 / 100. Judging from the level of scientific argumentation skills of students based on a modified aspect, which is the highest percentage is only at level $1(39.8 \%)$ where students can make a claim, however, the number is still very small even less than half the total number of all students. In this study, the most challenging aspect for students is the ability to present a rebuttal aspect. It is seen that only a small proportion (4.6\%) students were able to give a rebuttal, while almost all students $(95.4 \%$ ) have not been able to level 5 .

Claims are answers to research questions. The evidence then approves this claim. The nature of the evidence used in the argument is then assured by what is used as a reason. Component argument consists of observations, measurements, analysed or even findings from other studies that have been collected, then completed. The proof, in other words, consists of the data and explanations about it. The argument consideration component, in contrast, debates on decisions used to explain the relevance of the evidence used in the argument and Justifies. Proof of evidence that is often submitted for approval of the evidence in the 
concept, theory, or essential thinking supports that thought or Methodical during the investigation. A claim is an answer to a statement with evidence that includes measurements or observations and is relevant to support a particular claim, based on the results of reasoning [18].

Common difficulties faced by students are not being able to explain scientific explanations. It is failing to present sufficient and appropriate evidence for their claims, failing to link evidence with appropriate scientific principles, and not clearly interpreting their inferences and articulating their relationship between evidence and claims [7]. Skills in the aspect of claim can be in the form of debating several different claims [19]. Students who are not able to give good reasons for the claims they present/tend to be caused by not paying attention to cognitive and scientific aspects [20].

Warrant combines scientific principles and ideas, functioning as the relationship between claims and evidence [18]. The explanation is given shows the relationship between data and claims with the correct scientific concept and can lead to misconceptions if not given a clear warrant [21]. Students may be difficult to provide a proper warrant because they have not presented several indicators of words such as "so" or "because". These words are useful to identify what is being inferred from the claim filed or why a conclusion has been drawn, so warranties often serve as explanatory [22]. The level of students in the warrant aspect is still weak because they have difficulty connecting the statements with the data. Not even a number of those who do not write one of the claims or data. Though, the warrant is a logical sentence that connects data with claims in scientific argumentation pattern [23, 24].

Backing provides the fact that is supporting a warrant. It is an underlying assumption that is usually considered to be mutually agreed upon and provides justification for specific warrant [25]. Many claims, warranties or data are not supported by reliable information. It seems that students tend to give convincing opinions that a claim is sufficient. They rely heavily on their thinking by ignoring relevant information [26]. Student arguments at the backing level are still low because the supporting evidence is unclear, incorrect, or not connected with the claim. Good backing contains reasons with at least one evidence that supports and has a connection to the claim [27].

The rebuttal is a statement that a claim is wrong based on evidence and reasoning which disagree with a claim but do not make a new claim [28]. As a statement against the claim [29], rebuttal becomes the most challenging aspect of scientific argumentation skill. The rebuttal aspect is marked by the presence of a reply that can be identified [27]. However, in this study, almost all students were not able to present a counterclaim (rebuttal) clearly or even not at all present rebuttal. They couldn't use higher patterns of argumentation, including rebuttal [30].

There are three types of rebuttal in scientific argumentation, including opinion or rebuttal consisting of personal attacks, a rebuttal consisting of own views, and rebuttal consisting of scientific evidence [31]. Based on the type of rebuttal, almost all students have difficulty in presenting the refutation, primarily, based on the denial of scientific evidence. Several things cause the low level of students' rebuttal. Similar [32] statements conveyed only repeat the arguments stated earlier, rebuttal delivered without reason, present a new argument that does not directly deny the counter-argument said previously.

There are two playing keys to involving students in scientific argumentation [8]. First, argumentation is the primary practice of science, and as such must become the core of science education. Second, discuss the norms of scientific argumentation lead students to understand the epistemological foundations of scientific practice. Besides, According to [33] required individuals who approve and criticize whether and support access to claims.

\section{CONCLUSION}

Sequentially the level of scientific argumentation ability of students is level 1 (claim) makes statements, level 2 (data) presents data/facts, level 3 (warrant) connects data and claims through evidence or theory, level 4 (backing) supports claims with a mathematical calculation or picture, and level 5 (Rebuttal) provides a rebuttal to the statement. Based on the findings, it can be concluded that the items declared valid test to measure the level of scientific argumentation ability learners. Several items were developed in good condition by INFIT MNSQ, difficulty, and overall, in reliability.

Modification of the level of scientific argumentation ability of students in sequence starting from the highest level (level 5) is a claim, data/fact, warrant, backing, and rebuttal. Also, the study concluded that students' ability to scientific arguments at this school are still at low levels; where most students are only able to be at the lowest level 1. Most students have not been able to present an argument that can be categorized as a scientific argument. The student characterizes it answers, none of which correspond to the capability of scientific argumentation. 


\section{REFERENCES}

[1] L. Kuhn and B. J. Reiser, "Students Constructing and Defending Evidence-Based Scientific Explanations," Annu. Meet. Natl. Assoc. Res. Sci. Teaching, Dallas, TX, vol. 1, no. 1, pp. 1-35, 2005.

[2] M. Scarmadalia, "Collective cognitive responsibility for the advancement of knowledge," Lib. Educ. a Knowl. Soc., vol. 1 , no. 97, pp. 67-98, 2002.

[3] A. Zohar and F. Nemet, "Fostering students' knowledge and argumentation skills through dilemmas in human genetics," J. Res. Sci. Teach., vol. 39, no. 1, pp. 35-62, 2002.

[4] Ö. Acar, "Scientific reasoning, conceptual knowledge, \& achievement differences between prospective science teachers having a consistent misconception and those having a scientific conception in an argumentation-based guided inquiry course," Learn. Individ. Differ., vol. 30, no. 30, pp. 148-154, 2014.

[5] V. Sampson and S. Schleigh, Scientific argumentation in biology: 30 classroom activities, NSTA Press, 2013.

[6] N. M. Mirza and A. N. Perret-Clermont, Argumentation and education: Theoretical foundations and practices, Springer, 2009.

[7] C. C. Hsu, C. H. Chiu, C. H. Lin, and T. I. Wang, "Enhancing skill in constructing scientific explanations using a structured argumentation scaffold in scientific inquiry," Comput. Educ., vol. 91, no. 15, pp. 46-59, 2015.

[8] S. Erduran and M. Jimenez-Aleixandre, Argumentation in Science Education: Perspectives from Classroom-Based Research, Springer, 2007.

[9] Wardani, A. Dewi, L. Yuliati, and A. Taufiq, "The ability of scientific argumentation and physics problem solving for high school students on force and motion material (in Bahasa)," in Pros. Semnas Pendidikan IPA Pascasarjana UM., vol. 1, no. 1, pp. 13-28, 2016.

[10] T. N. Ain, H. A. C. Wibowo, A. Rohman, and U. A. Deta, "The scientific argumentation profile of physics teacher candidate in Surabaya," in Journal of Physics: Conference Series, vol. 997, no. 1, pp. 012025, 2018.

[11] R. Hirschheim, D. M. Murungi, and S. Peña, "Witty invention or dubious fad? Using argument mapping to examine the contours of management fashion," Inf. Organ., vol. 22, no. 1, pp. 60-84, 2012.

[12] A. Hunter, "Elements of argumentation," in Lecture Notes in Computer Science (including subseries Lecture Notes in Artificial Intelligence and Lecture Notes in Bioinformatics), 2007.

[13] J. Osborne, S. Erduran, and S. Simon, "Enhancing the quality of argumentation in school science," J. Res. Sci. Teach., vol. 41, no. 10, pp. 994-1020, 2004.

[14] B. Sumintono and W. Widhiarso, Rasch modeling application in educational assessments (in Bahasa), Trim Komunikata, 2015.

[15] P. G. F. Cheng et al., "Psychologist in a Pocket: Lexicon Development and Content Validation of a Mobile-Based App for Depression Screening," JMIR mHealth uHealth, vol. 4, no. 3, pp. e88, 2016.

[16] C. Ayre and A. J. Scally, "Critical values for Lawshe's content validity ratio: Revisiting the original methods of calculation,” Meas. Eval. Couns. Dev., vol. 47, no. 1, pp. 79-86, 2014.

[17] C. H. Lawshe, "A quantitative approach to content validity," Pers. Psychol., vol. 28, no. 4, pp. 563-575, 1975.

[18] M. González-Howard, K. L. McNeill, L. M. Marco-Bujosa, and C. P. Proctor, "Does it answer the question or is it French fries?': an exploration of language supports for scientific argumentation,” Int. J. Sci. Educ., vol. 39, no. 5, pp. 528-547, 2017.

[19] R. Katsh-Singer, K. L. Mcneill, and S. Loper, "Scientific Argumentation for All? Comparing Teacher Beliefs About Argumentation in High, Mid, and Low Socioeconomic Status Schools," Sci. Educ., vol. 100, no. 3, pp. 410-436, 2016.

[20] J. Grooms, V. Sampson, and P. Enderle, "How concept familiarity and experience with scientific argumentation are related to the way groups participate in an episode of argumentation," J. Res. Sci. Teach., vol. 55, no. 9, pp. 1264-1286, 2018.

[21] L. L. Heng, J. Surif, and C. H. Seng, "Malaysian Students' Scientific Argumentation: Do groups perform better than individuals?" Int. J. Sci. Educ., vol. 37, no. 3, pp. 505-528, 2015.

[22] A. Moon, C. Stanford, R. Cole, and M. Towns, "The nature of students' chemical reasoning employed in scientific argumentation in physical chemistry," Chem. Educ. Res. Pract., vol. 17, no. 2, pp. 353-364, 2016.

[23] F. A. Faize, W. Husain, and F. Nisar, "A critical review of scientific argumentation in science education," Eurasia J. Math. Sci. Technol. Educ., vol. 14, no. 1, pp. 475-483, 2018.

[24] C. Y. Tsai, "Improving Students' PISA Scientific Competencies Through Online Argumentation," Int. J. Sci. Educ., vol. 37, no. 2, pp. 321-339, 2015.

[25] J. Pimvichai, K. Buaraphan, and C. Yuenyong, "Development of Grade 10 Students' Scientific Argumentation through the Science-Technology-Society Learning Unit on Work and Energy," J. Technol. Sci. Educ., vol. 9, no. 3, pp. 428, 2019.

[26] M. S. Hayat et al., "Comparison of argumentation skill in science and non-science undergraduate students," in Journal of Physics: Conference Series, vol. 1157, no. 2, pp. 1-6, 2019.

[27] Q. T. Liu, B. W. Liu, and Y. R. Lin, "The influence of prior knowledge and collaborative online learning environment on students' argumentation in descriptive and theoretical scientific concept," Int. J. Sci. Educ., vol. 41, no. 2, pp. 165-187, 2019.

[28] B. B. Frey, J. D. Ellis, J. A. Bulgreen, J. C. Hare, and M. Ault, "Development of a Test of Scientific Argumentation," Electron. J. Sci. Educ., vol. 19, no. 4, pp. 1-18, 2015.

[29] H. Y. Ho et al., "Above-and below-average students think differently: Their scientific argumentation patterns," Think. Ski. Creat., vol. 100607, no. 31, pp. 1-21, 2019. 
[30] O. Sengul, "Document Features in Physics Tutorials to Promote College Students' Use of Argumentation," Eur. J. Phys. Educ., vol. 10, no. 2, pp. 53-65, 2019.

[31] Y. R. Lin and J. F. Hung, "The analysis and reconciliation of students' rebuttals in argumentation activities," Int. J. Sci. Educ., vol. 38, no. 1, pp. 130-155, 2016.

[32] Y. T. Chien and C. Y. Chang, "Supporting socio-scientific argumentation in the classroom through automatic group formation based on students' Real-time responses," in Science Education in East Asia: Pedagogical Innovations and Research-informed Practices, Springer, 2015.

[33] M. S. Khine, Perspectives on scientific argumentation: Theory, practice and research. Springer, 2014. 